\title{
Effects of Chemical Solutions on the Toughness of Polypropylene
}

\author{
Hirokazu WadA, ${ }^{\dagger}$ Yasuo Suzuki, Kenzo OKamoto, and Masaru IshIKawa \\ Department of Polymer Science and Engineering, Yamagata University, \\ 4-3-16 Jonan, Yonezawa 922-8510, Japan
}

(Received February 1, 2005; Accepted August 5, 2005; Published December 15, 2005)

\begin{abstract}
The mechanism for the degradation of isotactic polypropylene ( $i-\mathrm{PP})$ due to treatment with heated chemical solutions was examined by three-point bending tests with U-notched bars in a plane strain state. When $i$ PP was treated with nitric acid solution, tie molecules that connect lamellar crystals were ruptured near the surface of the specimens. This resulted in a decrease in molecular weight and craze strength at the surface. Consequently, the surface craze was easily transformed into cracks. Since the edges of the cracks thus formed was sharp with small radii, the strong strain constraint caused stress concentration, resulting in a brittle fracture of the material. When $i$-PP was treated with sodium hydroxide and sulfuric acid solutions, increase in yield stress due to heat treatment was the dominant factor for decrease in toughness. [DOI 10.1295/polymj.37.877]

KEY WORDS Polypropylene / Degradation / Chemical Solution / Toughness / Tie Molecules / Molecular Weight / Surface Craze /
\end{abstract}

Molded parts of polymeric materials such as polypropylene (PP) and glass fiber reinforced PP are frequently used under stress loading when treated with heated acid and alkaline solution. When molded parts are used under such conditions, degradation is caused, and strength or toughness decreases. Finally, cracks occur in molded parts, and are fractured. Therefore, the prediction of durability of molded parts and improvement are required in order to use molded parts under such conditions.

The general modes of the fracture of polymeric materials are brittle facture caused by a small strain and ductile fracture caused after large plastic deformation. Brittle fracture of most polymeric materials, such as PP, occurs when the fibrillar bundles are ruptured by a strain constraint-induced stress concentration, whose strength exceeds the craze strength in a local plastic zone comprising voids and fibrils. ${ }^{1-7}$ The strength of stress concentration caused by the strain constraint depends on boundary conditions, such as the shape of molded parts, and material constants, such as the modulus and yield stress. However, ductile fracture occurs when the stress exerted on the fibril, formed by a uniform and large plastic deformation, exceeds critical strength. The plastic deformation of polymeric materials is caused by local kinks of molecular chains in the case of an amorphous glass polymer ${ }^{8,9}$ and by slip of the $C$-axis of the lamellar crystal for a crystalline polymer. ${ }^{10}$ The yield stress of PP, a crystalline polymer, depends on the thickness of the lamellar crystal, i.e., degree of crystallization. It does not depend on the length of the molecular chain. Since the strength of the fibril depends on the strength of interaction along the molecular chain, it increases with the molecular weight. Therefore, polymers with large molecular weight are strong and tough. ${ }^{11-13}$

It should be noted that a PP-immersed chemical solution, such as an acid or alkaline solution, penetrates the amorphous region between the lamellar crystals and may rupture the molecular chain. Rupture of the molecular chain is considered to hinder the transmission of the force between lamellar crystals and influence the strength of the oriented fibrils. The degradation and detailed fracture mechanism of PP under such unusual conditions have not yet been clarified.

This study investigates the mechanical properties of PP immersed in various chemical solutions, especially the degradation mechanism of toughness, and determines the dominant structural causes of degradation.

\section{EXPERIMENTAL}

\section{Materials and Chemical Solutions}

The material used in degradation was commercial grade isotactic PP ( $i$-PP) with number-average molecular weight $\left(M_{\mathrm{n}}\right)$ of $4.86 \times 10^{4}$, weight-average molecular weight $\left(M_{\mathrm{w}}\right)$ of $2.15 \times 10^{5}$, polydispersity coefficient $\left(M_{\mathrm{w}} / M_{\mathrm{n}}\right)$ of 4.4 , and melt flow rate of $5.2 \mathrm{~g} /$ $10 \mathrm{~min}$ (at $503 \mathrm{~K}$ ). Chemical solutions were water, sodium hydroxide solution $(\mathrm{NaOH})$, sulfuric acid solution $\left(\mathrm{H}_{2} \mathrm{SO}_{4}\right)$, and nitric acid solution $\left(\mathrm{HNO}_{3}\right)$ at 20 wt $\%$ and treatment temperature, $353 \mathrm{~K}$.

\section{Preparation of Specimens}

A dumbbell specimen with thickness of $1 \mathrm{~mm}$, width $6 \mathrm{~mm}$, and gauge length, $20 \mathrm{~mm}$ was used to

${ }^{\dagger}$ To whom correspondence should be addressed (E-mail: ytc-01@ nihon-filter.co.jp). 
estimate stress-strain curves. U-notched bars were used for toughness tests. The specimens were injection molded at a barrel temperature of $493 \mathrm{~K}$ and mold temperature of $323 \mathrm{~K}$. The U-notched bar length was $50 \mathrm{~mm}$, cut from rectangular bars having width of $12.7 \mathrm{~mm}$, thickness $6.4 \mathrm{~mm}$, and length, $120 \mathrm{~mm}$. A circular notch with radius of $0.5 \mathrm{~mm}$ was shaped by machining with a convex milling cutter. Ligament thickness was $4 \mathrm{~mm}$. The specimens were cooled with water to prevent increase in temperature during machine processing.

\section{Degradation Test}

The specimens were placed in round-bottom flasks, each containing a different solution for degradation conducted at 7, 14, and $21 \mathrm{~d}$. For a discussing the effects of chemical solutions and temperature on degradation, heat treatment was performed at $353 \mathrm{~K}$.

\section{Evaluation of Mechanical Properties}

Yield stress was evaluated from stress-strain curves from uniaxial tensile test at a strain rate of $0.25 \mathrm{~min}^{-1}$ and $296 \mathrm{~K}$. Toughness of PP was evaluated by threepoint bending tests with U-notched bars in a plane strain state. The specimens were loaded using an Instron-type test machine (Auto Graph, Shimadzu AG-E) at a bending rate of $200 \mathrm{~mm} \mathrm{~min}^{-1}$ with span length of $40 \mathrm{~mm}$. Temperature dependency of modulus was evaluated using a dynamic viscoelasticity machine (Rheometrics Solids Analyzer RSAII) at a frequency of $10 \mathrm{~Hz}$. The specimens were heated at $2 \mathrm{~K} \mathrm{~min}^{-1}$.

\section{Morphological Analysis of Deformation Mode Caused by Degradation}

Three-point bending tests were made to analyze the deformation mode of U-notched bars in a plane strain state, caused by degradation. To prepare the specimens, we cut thin sections-approximately $25 \mu \mathrm{m}$ thick-perpendicular to the plane of the initial notch using a conventional microtome. The sections were observed using an optical microscope (Olympus, BH2) to study the morphology of the crazes and plastic deformation zone. ${ }^{14}$ The surfaces of cryogenically fractured specimens were observed using a scanning electron microscope (JEOL, JSM-5310) to examine the microstructure of the plastic deformation zone. The specimens for the bending tests were first immersed in a liquid nitrogen bath for $5 \mathrm{~min}$ and then broken perpendicular to the plane of the notch immediately after removal from the bath. Since the strain recovery during the unloading period significantly influences the morphology of the deformation zone, deformation by three-point bending was remedied by an epoxy resin, ${ }^{15}$ consisting of 100 parts per hundred of resin (phr) of bisphenol A type epoxy resin (Mitsui
Chemicals, EPOMIK140) and $60 \mathrm{phr}$ of polyamideamine resin (Air Producs, Anquamide506).

\section{Evaluation of Degree of Crystallization}

The degree of crystallization was determined by differential scanning calorimetry (DSC, Perkin Elmer DSC7). The degree of crystallization index $\left(X_{\mathrm{C}}\right)$ was calculated as follows:

$$
X_{\mathrm{C}}=\frac{\Delta H^{*}(P P)}{\Delta H^{0}(P P)}
$$

where $\triangle H^{*}(P P)$ is bulk enthalpy of fusion per gram of PP and $\triangle H^{0}(P P)$ is heat of fusion per gram of $100 \%$ crystalline PP $(209 \mathrm{~J} / \mathrm{g})$. The specimens were heated at $10 \mathrm{~K} \mathrm{~min}^{-1}$.

\section{Evaluation of Molecular Weight}

Change in molecular weight with degradation was evaluated from styrene conversion using high-temperature gel permeation chromatography (GPC, Waters 150C ALC/GPC).

\section{RESULTS}

\section{Changes in Mechanical Properties with Degradation}

Stress-Strain Curves. Figure 1 shows the effects of degradation on stress-strain curves caused by chemical solutions. The yielding of untreated $i$-PP occurred at a strain of approximately $10 \%$, necking with locally concentrated strain. The necking spread over the whole specimen length at strain of approximately $400 \%$. Stress then increased by orientation hardening. In treatment with heat, water, $\mathrm{NaOH}$, and $\mathrm{H}_{2} \mathrm{SO}_{4}$, breaking occurred during increase in stress after necking. With $\mathrm{HNO}_{3}$ treatment, breaking occurred before necking spread over the entire specimen treated for $7 \mathrm{~d}$, and then before yielding for treatment over $14 \mathrm{~d}$. Regardless of chemical solution, breaking strain tended to reduce with the period. Figure 2 shows change in yield stress with the period. Regardless of chemical solution, yield stress increased with the period.

Change in Toughness with Degradation. Fracture of $i$-PP with number-average molecular weight of $4.86 \times 10^{4}$ was modeled in the following manner. When the local plastic zone spread in the direction of ligament thickness from the edge of a circular notch under a plane strain, general yielding occurred before maximum stress as the edge of the local plastic zone reached craze strength. Strain at the edge of the circular notch reached a critical level, and fracture occurred.

Figure 3 shows the effects of degradation on bending moment-displacement curves due to chemical solution. Displacement to fracture decreased rapidly due to degradation for $7 \mathrm{~d}$. Hence, reduction in toughness 

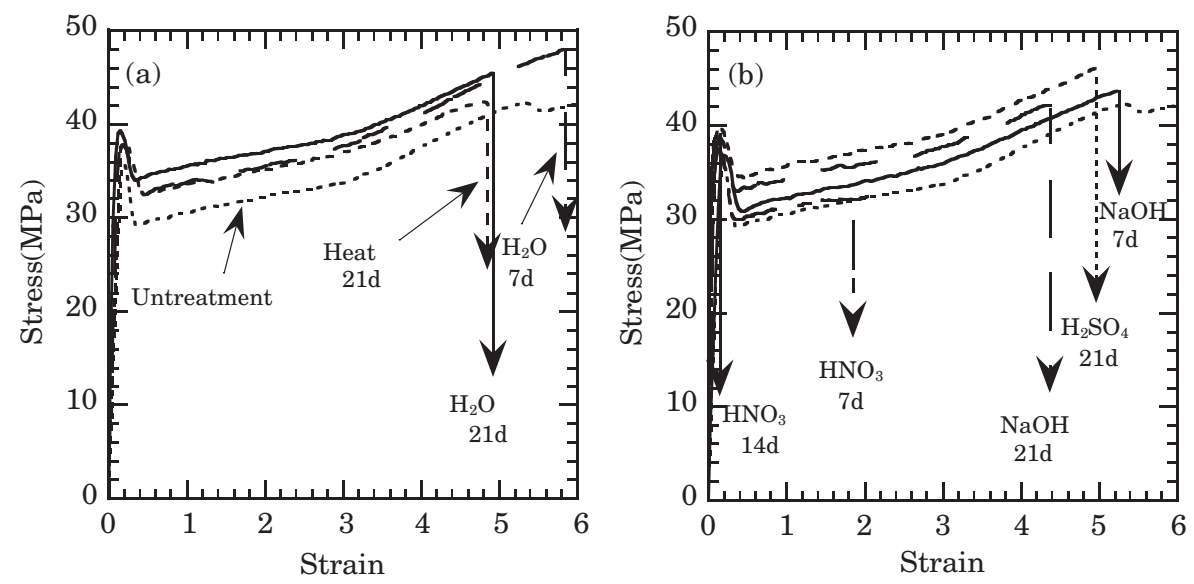

Figure 1. Effects of degradation on stress-strain curves (a) by heat treatment and $\mathrm{H}_{2} \mathrm{O}$ and (b) by $\mathrm{NaOH}_{2} \mathrm{H}_{2} \mathrm{SO}_{4}$ and $\mathrm{HNO}_{3}$.
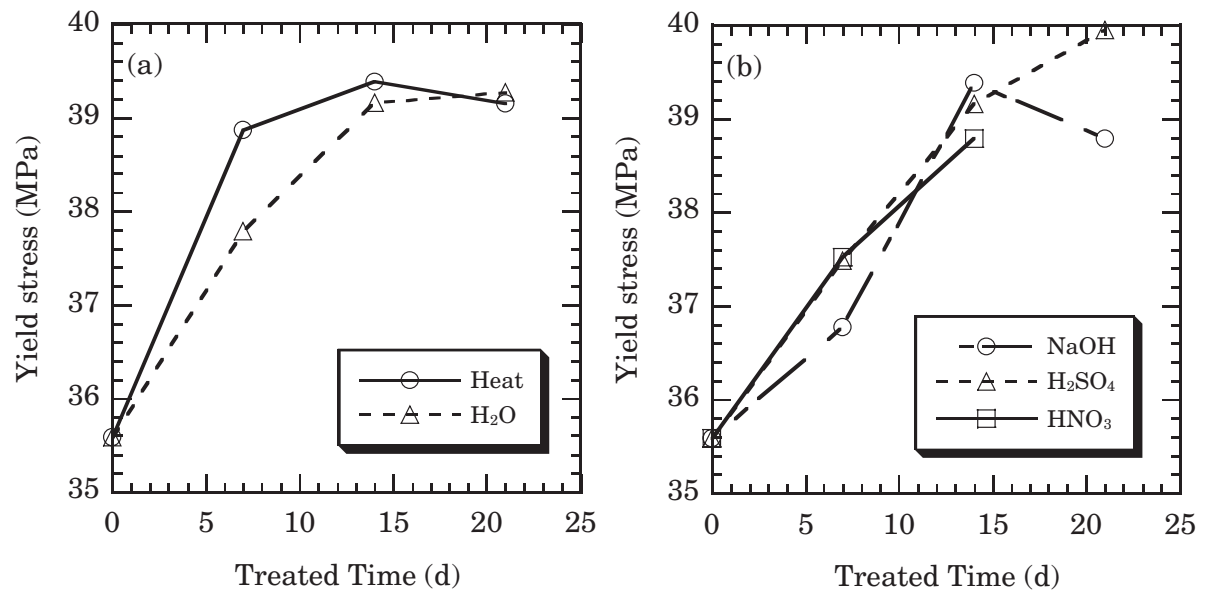

Figure 2. Time course of yield stress due to chemical solutions (a) by heat treatment and $\mathrm{H}_{2} \mathrm{O}$ and (b) by $\mathrm{NaOH}_{2} \mathrm{H}_{2} \mathrm{SO}_{4}$ and $\mathrm{HNO}_{3}$.
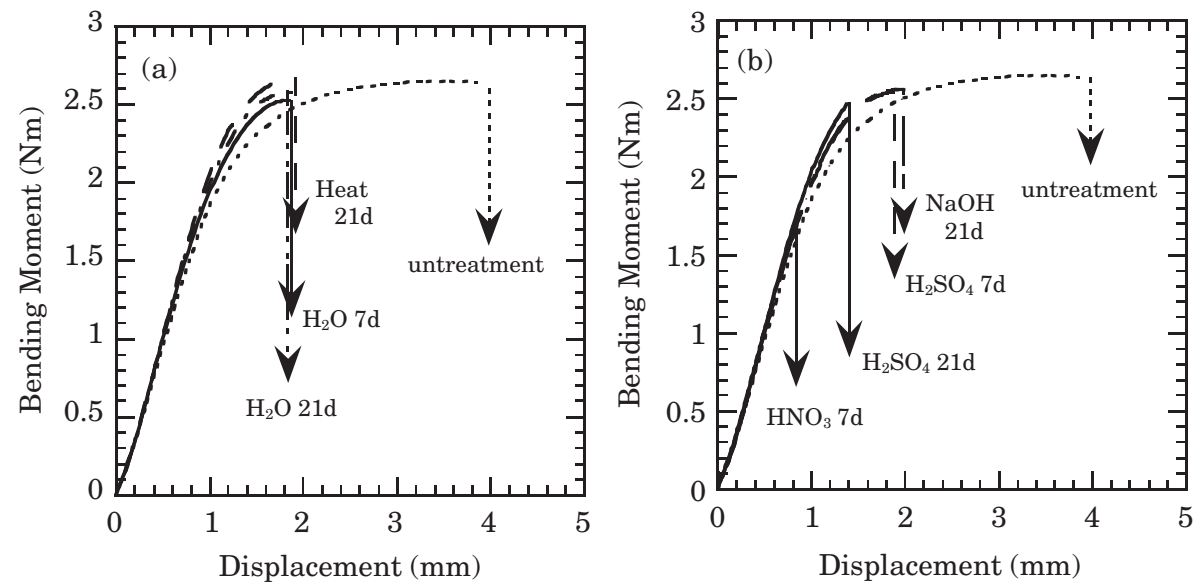

Figure 3. Effects of degradation on bending moment-displacement curves (a) by heat treatment and $\mathrm{H}_{2} \mathrm{O}$ and (b) by $\mathrm{NaOH}_{2} \mathrm{H}_{2} \mathrm{SO}_{4}$ and $\mathrm{HNO}_{3}$.

was observed. This reduction was small with treatment period, and displacement to fracture was approximately $2 \mathrm{~mm}$. With $\mathrm{HNO}_{3}$ treatment, deformation mode changed from ductile fracture to brittle fracture at $7 \mathrm{~d}$.

Figure 4 shows change in fracture energy with the period till the fracture. $\mathrm{HNO}_{3}$ treatment obviously leads to greater reduction in toughness than treatment with other chemical solutions. Toughness of the specimen when treated with other chemical solutions including water decreased slightly as compared with heat treatment.

Change in Temperature Dependency of Modulus of 

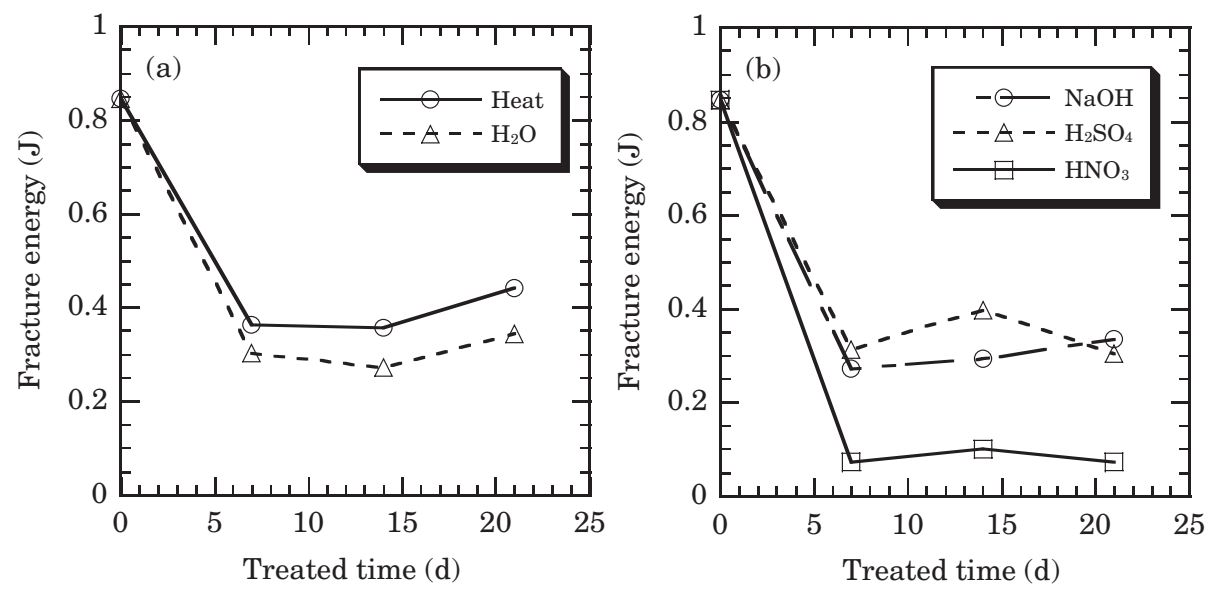

Figure 4. Time course of fracture energy (a) by heat treatment and $\mathrm{H}_{2} \mathrm{O}$ and (b) by $\mathrm{NaOH}, \mathrm{H}_{2} \mathrm{SO}_{4}$ and $\mathrm{HNO}_{3}$.
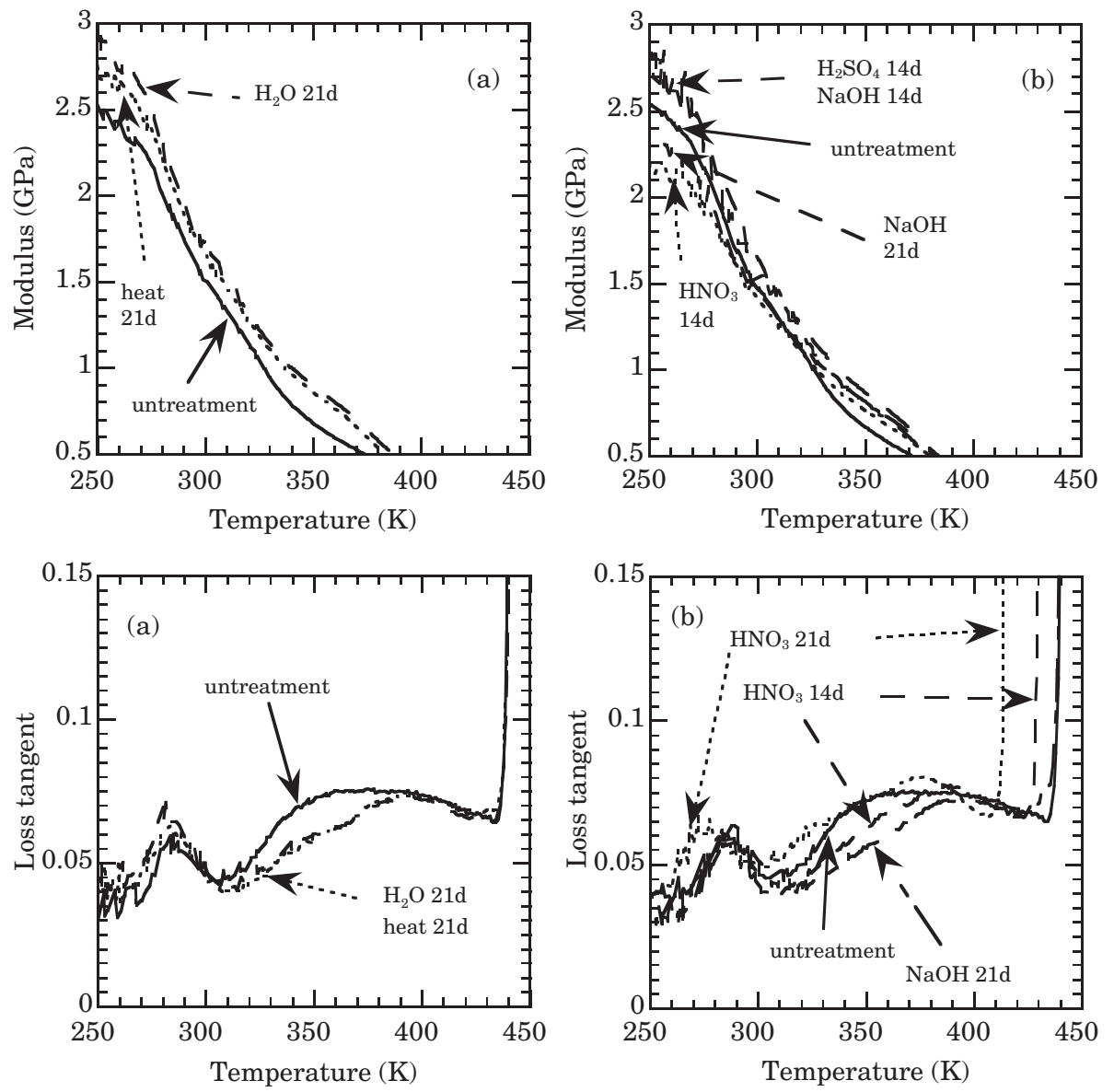

Figure 5. Effects of degradation on storage modulus and loss tangent to temperature dependency (a) by heat treatment and $\mathrm{H}_{2} \mathrm{O}$ and (b) by $\mathrm{NaOH}, \mathrm{H}_{2} \mathrm{SO}_{4}$ and $\mathrm{HNO}_{3}$.

Elasticity with Degradation. Degradation treatment at $353 \mathrm{~K}$ is considered to cause change in the degree of crystallization along with rupture of molecular chains. This causes the storage modulus to change. Figure 5 shows the effects of degradation on temperature dependency of the storage modulus and loss tangent. Treatment with heat and water increased the storage modulus with the period. For $21 \mathrm{~d}$, treatment with $\mathrm{NaOH}$ and $\mathrm{H}_{2} \mathrm{SO}_{4}$ first increased the storage modulus with degradation and then decreased it. Relaxation temperature due to the glass transition and crystal fusion was not influenced by degradation. For the $\mathrm{HNO}_{3}$-treated specimen, the storage modulus decreased with the period. The relaxation temperature due to the melting point decreased and the relaxation temperature due to the glass transition broadened. 

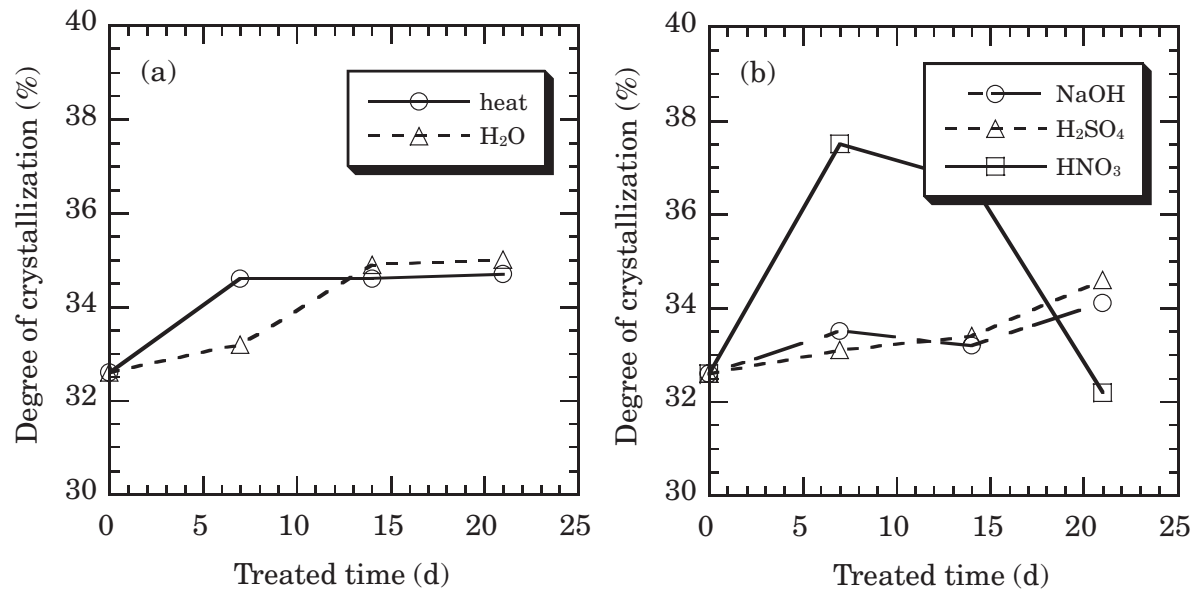

Figure 6. Time course of crystallization (a) by heat treatment and $\mathrm{H}_{2} \mathrm{O}$ and (b) by $\mathrm{NaOH}, \mathrm{H}_{2} \mathrm{SO}_{4}$ and $\mathrm{HNO}_{3}$.
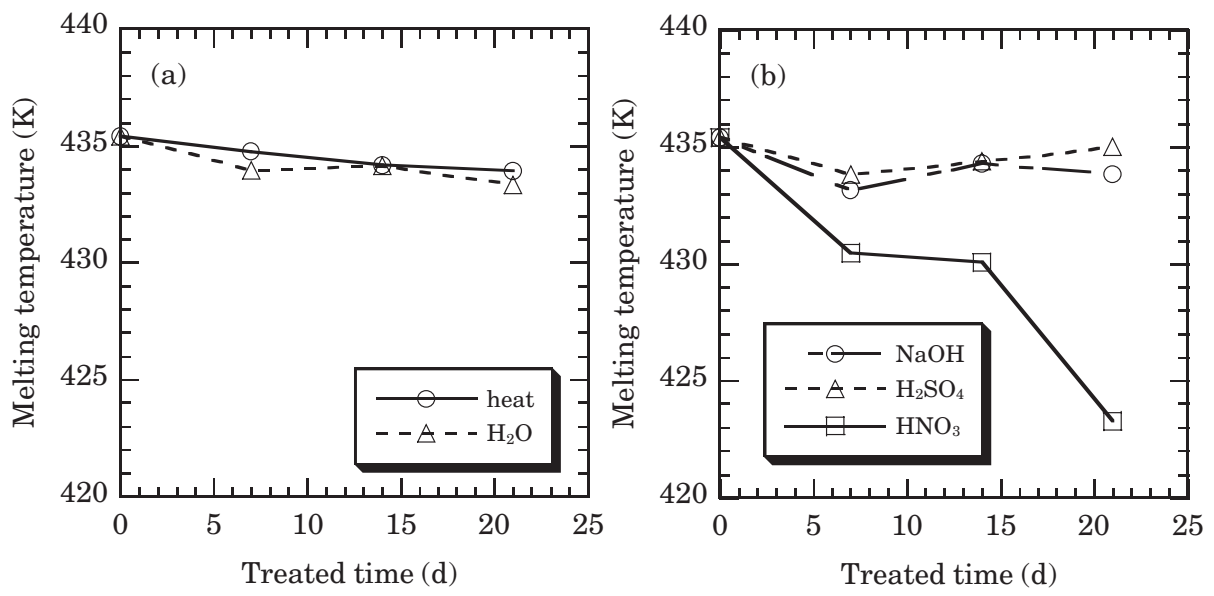

Figure 7. Time course of melting temperature (a) by heat treatment and $\mathrm{H}_{2} \mathrm{O}$ and (b) by $\mathrm{NaOH}, \mathrm{H}_{2} \mathrm{SO}_{4}$ and $\mathrm{HNO}_{3}$.

Change in the Degree of Crystallization and Melting Point with Degradation

Change in the degree of crystallization of polymeric materials occurs when lamellar crystals thicken by heat treatment, toughness decrease. ${ }^{16}$ Figure 6 shows change in the degree of crystallization with degradation. For the $\mathrm{HNO}_{3}$-treated specimen, crystallization drastically increased for treatment of $7 \mathrm{~d}$, and decreased again at $21 \mathrm{~d}$. Although crystallization increased with the period for other chemical solutions, increase was less than with heat treatment. Figure 7 shows change in the melting point with degradation. Although the melting point decreased with the duration of treatment in $\mathrm{HNO}_{3}$, no remarkable change was observed in the melting point with other solutions.

\section{Changes in Morphology of Plastic Zone with Degra- dation}

Figure 8 shows optical microphotographs of the plastic zone in a cross-section obtained from unbroken specimens treated for $21 \mathrm{~d}$, which were unloaded immediately before brittle fracture. The formation of a large plastic zone was observed for untreated $i$-PP. The size of the plastic zone decreased until a fracture due to degradation was observed. Strain was concentrated at the center of the plastic zone during treatment, was very remarkable for the $\mathrm{HNO}_{3}$-treated specimen, and surface crazes were formed.

\section{Change in the Microstructure of Plastic Zone with Degradation}

Figure 9 shows scanning electron microphotographs (SEMs) of the microstructure of the plastic zone. Figures 9a, 9b, and 9c show SEMs of specimens treated with heat, $\mathrm{NaOH}$, and $\mathrm{HNO}_{3}$, respectively, for $21 \mathrm{~d}$. The width of the strain-concentrated distortion zone in SEM of the $\mathrm{HNO}_{3}$-treated specimen was narrower than for specimens treated with $\mathrm{NaOH}$ and $\mathrm{HNO}_{3}$. The structure of the distortion zone changed according to the distance from the edge of the notch. A craze structure comprised of voids and fibrils was observed at the edge of the distortion zone located farthest from the edge of the notch. In heat- and $\mathrm{NaOH}-$ treated specimens, voids were observed at all other 


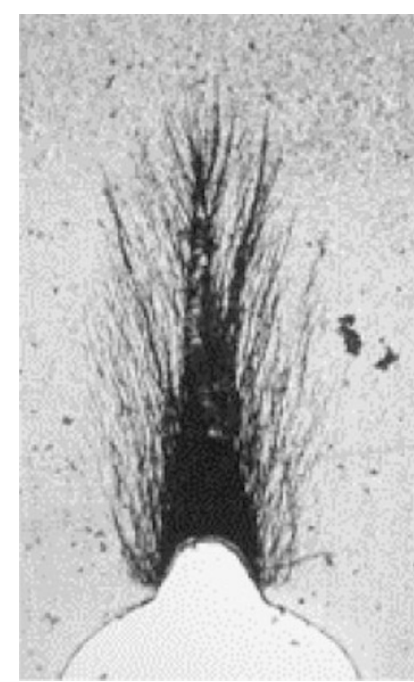

(a) Untreatment

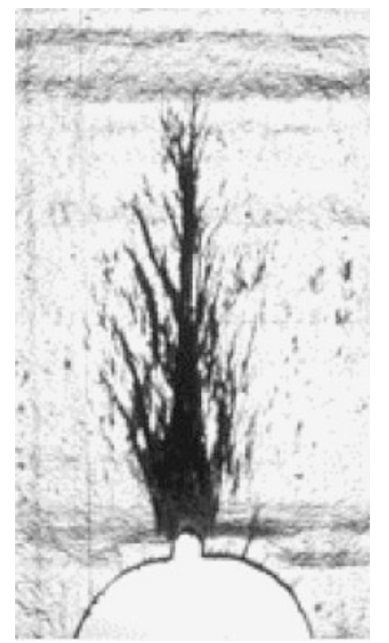

(d) $\mathrm{NaOH}$

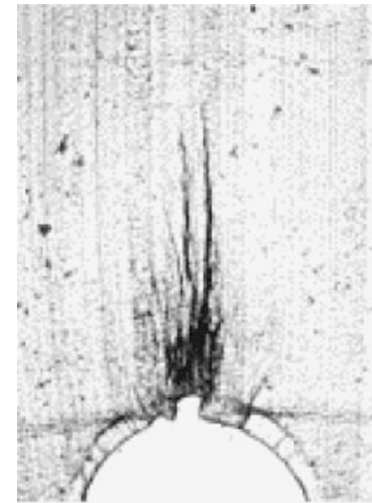

(b)Heat

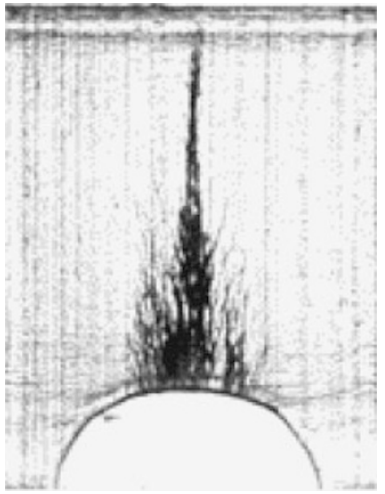

(e) $\mathrm{H}_{2} \mathrm{SO}_{4}$
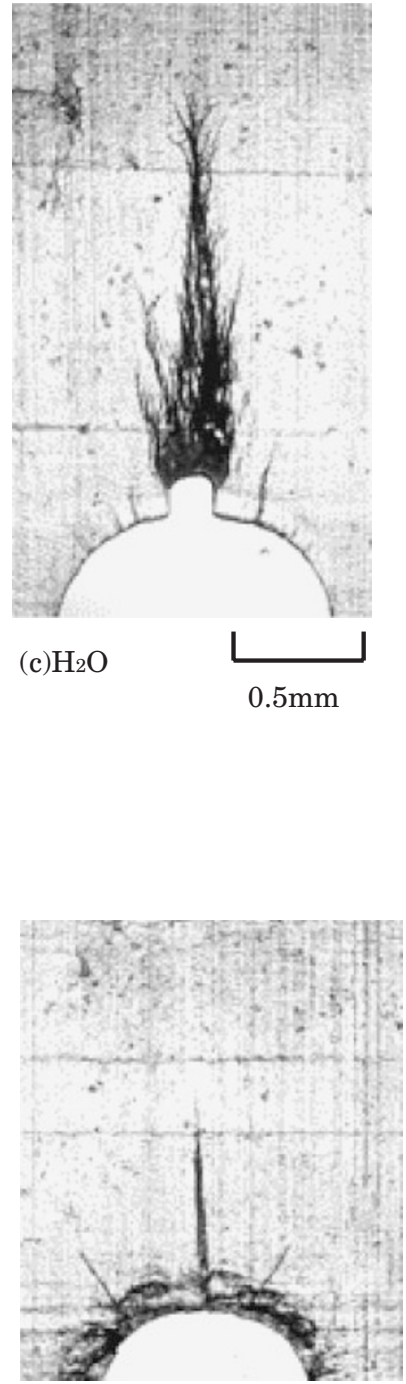

(f) $\mathrm{HNO}_{3}$

Figure 8. Optical microphotographs of the plastic zone at $21 \mathrm{~d}$.

than the edge of the notch. At the edge of the notch, heterogeneous voids formed within oriented structures. For the $\mathrm{HNO}_{3}$-treated specimen, such heterogeneous structures were observed near the center of the distortion zone, and oriented structures formed at the notch.

\section{Change in Fracture Section with Degradation}

Figure 10a shows a fracture section of a U-notched specimen in the three-point bending tests, after treatment for $21 \mathrm{~d}$ in water. The fracture nucleus was located a considerable distance from the edge of the notch, and crack began to propagate. Figure 10b shows a fracture section of a U-notched specimen in threepoint bending tests, after treatment for $21 \mathrm{~d}$ in $\mathrm{HNO}_{3}$. A flat region was observed within $0.23 \mathrm{~mm}$ from the edge of the notch, and a fibril, formed when voids expand due to plastic deformation, was observed at the edge. The size of this region increased with the treatment period. This fibril region might be created by cracks formed in the surface craze region before macroscopic fracture. Figure 10c shows a fracture section of specimens in tensile tests, after treatment for $21 \mathrm{~d}$ in $\mathrm{HNO}_{3}$. The fracture section within $0.25 \mathrm{~mm}$ from the surface of the specimen was flat and differed in structure from that of the interior of the specimen.

\section{Change in Molecular Weight with Degradation}

Table I shows change in molecular weight corresponding to that of polystyrene with degradation. Molecular weight decreased with the period for $\mathrm{HNO}_{3}$, and molecular weight corresponding to $21 \mathrm{~d}$ decreased to less than half that of untreated specimens. Decrease in molecular weight for specimens with other treatment was not confirmed. 

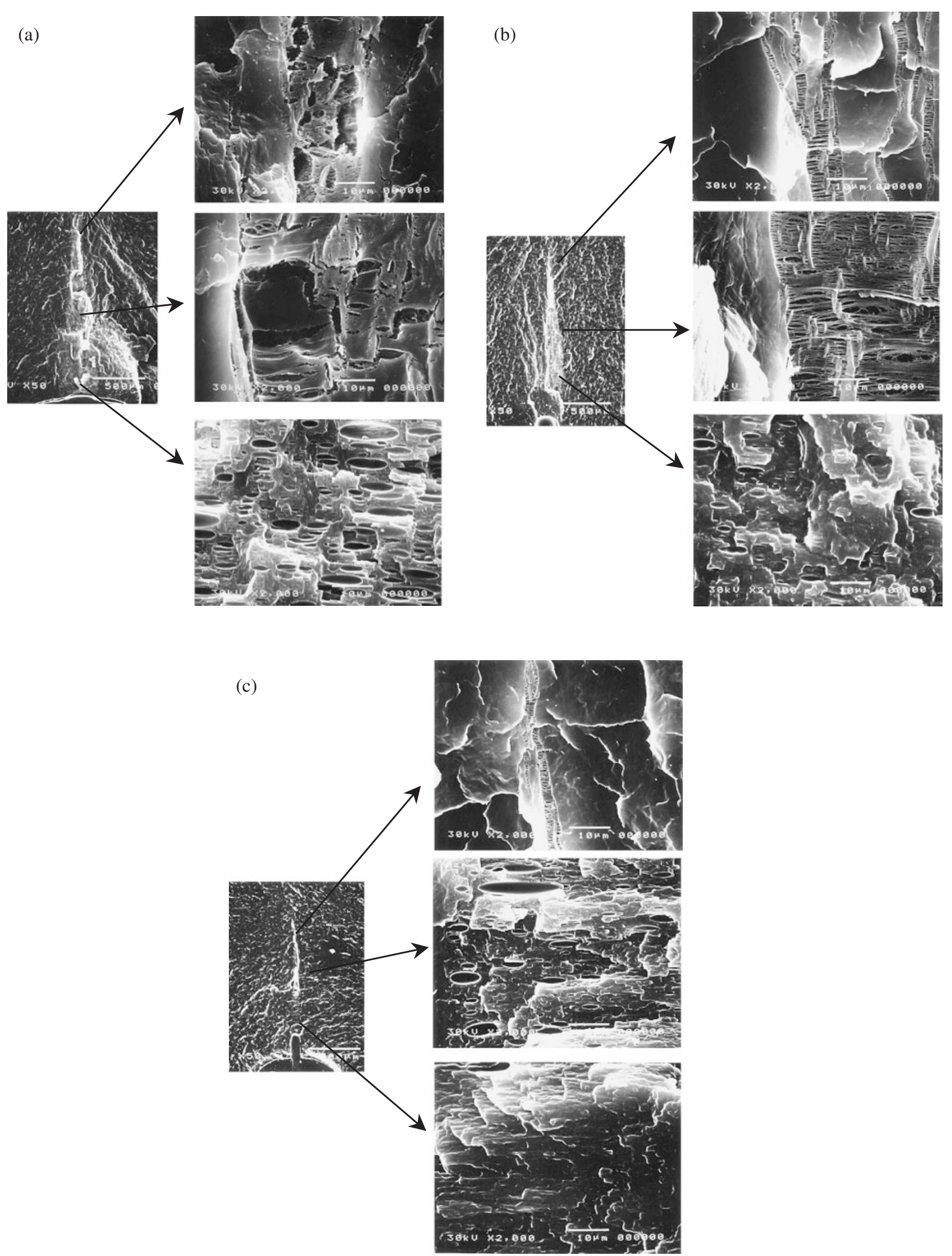

Figure 9. (a) Scanning electron microphotographs of the plastic zone due to heat treatment at $21 \mathrm{~d}$. (b) Scanning electron microphotographs of the plastic zone due to $\mathrm{NaOH}$ treatment at $21 \mathrm{~d}$. (c) Scanning electron microphotographs of the plastic zone due to $\mathrm{HNO}_{3}$ treatment at $21 \mathrm{~d}$. 


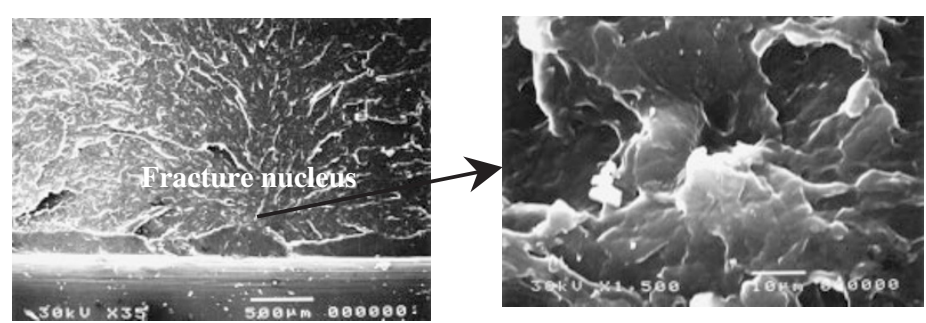

(a)

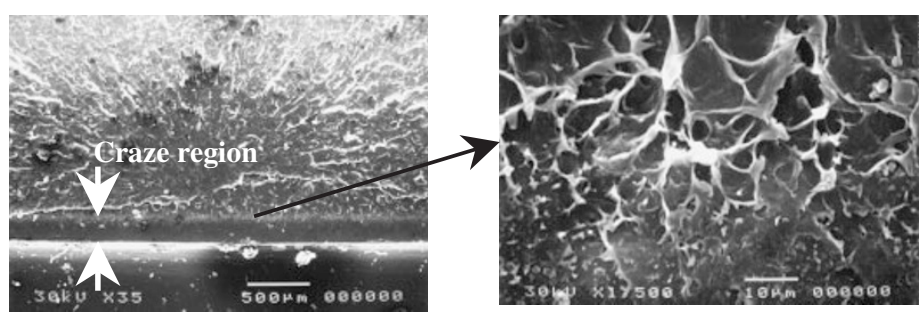

(b)

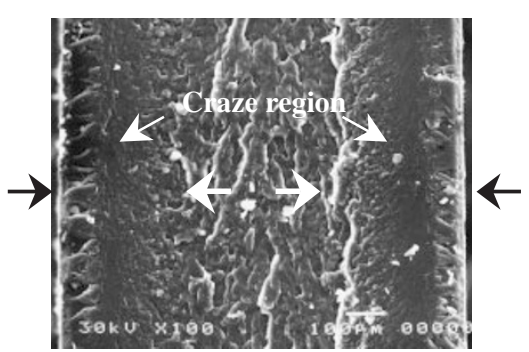

(c)

Figure 10. Scanning electron microphotographs of fracture surface (a) in $\mathrm{H}_{2} \mathrm{O}$ for $21 \mathrm{~d}$ on U-notched bar, (b) in $\mathrm{HNO}_{3}$ for $21 \mathrm{~d}$ on U-notched bar and (c) in $\mathrm{HNO}_{3}$ for $21 \mathrm{~d}$ on uniaxial tensile specimen.

Table I. Change in molecular weight corresponding to that in polystyrene with degradation

\begin{tabular}{lcccc}
\hline $\begin{array}{l}\text { Chemical } \\
\text { solutions }\end{array}$ & $\begin{array}{c}\text { Treated } \\
\text { time }\end{array}$ & $M_{\mathrm{n}} / 10^{5}$ & $M_{\mathrm{w}} / 10^{5}$ & $M_{\mathrm{w}} / M_{\mathrm{n}}$ \\
\hline untreatment & - & 1.43 & 8.72 & 6.1 \\
$\mathrm{H}_{2} \mathrm{O}$ & $21 \mathrm{~d}$ & 1.41 & 8.77 & 6.2 \\
$\mathrm{NaOH}$ & $21 \mathrm{~d}$ & 1.36 & 8.79 & 6.5 \\
$\mathrm{H}_{2} \mathrm{SO}_{4}$ & $21 \mathrm{~d}$ & 1.42 & 8.66 & 6.1 \\
$\mathrm{HNO}_{3}$ & $7 \mathrm{~d}$ & 1.07 & 4.23 & 4.0 \\
& $14 \mathrm{~d}$ & 0.85 & 2.91 & 3.4 \\
& $14 \mathrm{~d}^{\mathrm{a}}$ & 0.34 & 0.96 & 2.8 \\
& $21 \mathrm{~d}$ & 0.62 & 2.11 & 3.4 \\
\hline
\end{tabular}

${ }^{\mathrm{a}}$ Molecular weight corresponding to that in polypropylene.

\section{DISCUSSION}

\section{Fracture Mechanism of $i-P P$}

A load applied on molded parts of $i$-PP causes stress concentration due to strain constraint. Plastic deformation occurs when the strength of stress concentration exceeds yield stress. Stress concentration due to plastic constraint peaks at the edge of the plas- tic zone, and expansion stress occurs. Voids are formed by expansion stress, and if the state of stress around the voids satisfies the plastic unstable conditions that cause an unstable growth of voids, a craze with locally-concentrated strains forms. This craze is comprised of oriented fibrils and voids lying between fibrils. Therefore, the plastic zone of $i$-PP is comprised of plastic zone that include these crazes. The brittle fracture occurs when maximum stress near the edge of the extended plastic zone exceeds the strength of fibrils that constitute the craze. In the case of $i$-PP, yield stress and density of voids, which determine the strength of the stress concentration, is not significantly dependent on molecular weight. However, craze strength decreases with decrease in number-average molecular weight. For $i$-PP with a number-average molecular weight of $4.86 \times 10^{4}$, stress concentration due to plastic constraint in the U-notched bar geometry cannot attain a level that would rupture fibrils in the crazes. Therefore, the plastic zone developed from the edge of the U-notch extends to the entire thickness of the specimen, and general yielding occurs. The fracture occurs when plastic strain at the edge of the notch reaches a critical level due to deformation. 


\section{Change in Fracture Conditions with Degradation}

Degradation with chemical solutions at $353 \mathrm{~K}$ changed the structures of crystallization and tiemolecular chains that connect lamellae in $i$-PP. When $i$-PP molded from a melting state at a temperature of $323 \mathrm{~K}$ is heat treated at $353 \mathrm{~K}$, crystallization increases with the thickness of the lamellar crystal. The plastic deformation of a crystalline polymer is caused by slip of the $C$-axis of the lamellar crystal. Therefore, yield stress increases with thickness of the lamellar crystal. Since the strength of stress concentration due to the plastic constraint caused by a local plastic deformation depends on the yield stress, stress concentration increases with yield stress. The ratio of the craze strength to the yield stress decreases, and stress caused by a small displacement at the edge of the plastic zone reaches the craze strength to cause brittle fracture. Therefore, toughness is reduced by heat treatment. Although increase in crystallization of the specimens treated in water, $\mathrm{NaOH}$, and $\mathrm{H}_{2} \mathrm{SO}_{4}$ is less than with heat-treated specimen, decrease in molecular weight is hardly noticeable. The effect of heat treatment is dominant factor for decrease in toughness.

Chemical solutions diffuse into an interlamellar amorphous region with low density. Lamellar crystals are connected by tie molecules, and play roles in transferring force. The modulus and yield stress of a crystalline polymer such as $i$-PP depend on the degree of crystallization and number of tie-molecular chains. The number of tie-molecular chains connecting lamellas and number of continuous folding in lamellar crystals can be evaluated with Krigbaum's crystal model. ${ }^{17,18}$ In $i$-PP having a tacticity of approximately 0.94 and molded by quenching from a melting state, the number of continuous folding in lamellar crystals is nearly seven. Molecular chains are connected with other crystals via tie-molecular chains in the amorphous region. In $i$-PP with a number-average molecular weight of $4.86 \times 10^{4}$, a molecular chain connects about ten lamellar crystals. ${ }^{12,14}$

Chemical solution diffusion into $i$-PP may be generally explained by Fick's model. As shown in Figure 11 , the concentration of chemical solution decreases with the distance from the surface of the specimen. Rupture of tie-molecular chains connecting lamellae increases with the concentration of the chemical solutions. Therefore, decrease in molecular weight with the rupture of tie-molecular chains is maximum at the surface of a specimen, and decreases toward the interior of the specimen. When a load is applied, force is transferred to lamellar crystals through tie-molecular chains. When stress applied to tie-molecular chains exceeds the stress causing slip of the $C$-axis of the lamellar crystal, plastic deformation occurs. Since $\mathrm{HNO}_{3}$ may rupture tie-molecular chains connecting lamellar

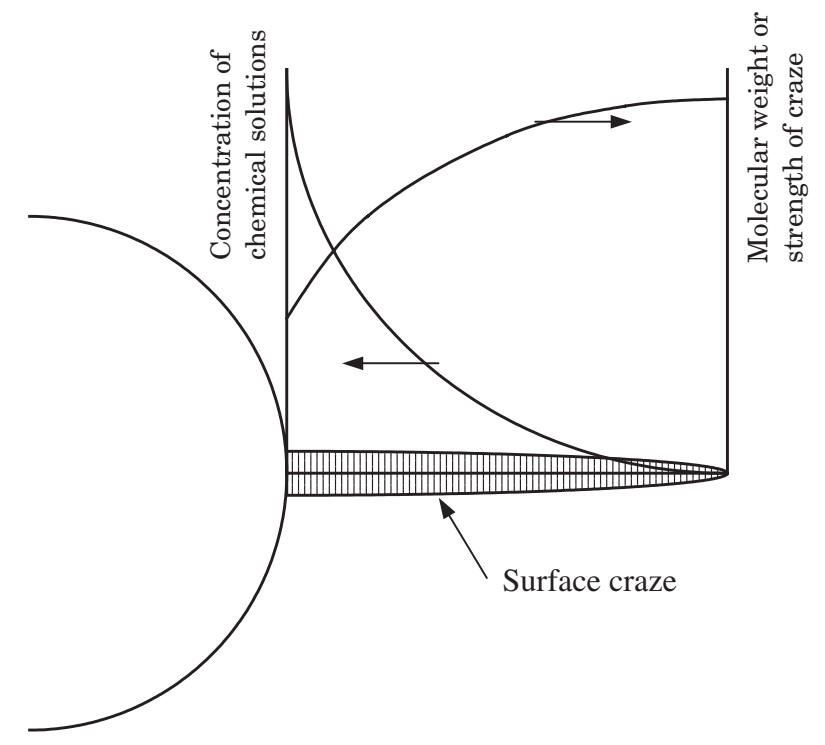

Figure 11. Distribution of strength of crazes near damaged surface.

crystals, the number of chains decreases. Consequently, the macroscopic yield stress should decrease. Since degradation tests with the chemical solutions carried out at $353 \mathrm{~K}$, lamella thickness increased due to the effects of heat treatment. Despite this increase, yield stress decreased compared to that of the specimen treated only with heat (Figure 2). Oriented fibrils form as the plastic deformation proceeds. The strength of the fibrils decreases with molecular weight. When a specimen was treated with $\mathrm{HNO}_{3}$ for $14 \mathrm{~d}$, the number-average molecular weight $\left(M_{\mathrm{n}}\right)$ decreased to $3.43 \times 10^{4}$. This estimation is the average for the entire specimen, and thus molecular weight at the surface may decrease further. Therefore, crazes easily form at the edge of the notch along with a locally small plastic zone due to the heterogeneity of the surface shape. This results in the development of cracks from points where crazes form. The cracks easily propagate in the region where the molecular weight decreases by chemical solutions. This propagation ends near the boundary of the diffusion region of the chemical solutions. Observation of the microstructure of the plastic zone and fractured section confirm the above mechanism for formation of cracks (Figures $10 \mathrm{~b}$ and 10c). Since cracks thus formed sharp edge with small radii, stress concentration occurs by strong plastic constraint. If the length of a crack satisfies the condition of unstable crack propagation, brittle fracture occurs. Thus, when tie molecular chains are ruptured by chemical solutions, sharp crack form, resulting in change in brittle fracture of polymeric materials.

\section{CONCLUSIONS}

The degradation mechanism of $i$-PP caused by heat- 
ed chemical solutions was examined by three-point bending tests with U-notched bars in a plane strain state. When treated with nitric acid $\left(\mathrm{HNO}_{3}\right)$ solution, molecular weight decreased with rupture of tie molecular chains that connect lamellar crystals near the surface of the specimen, resulting in the formation of crazes. Surface crazes transformed into cracks, causing brittle fracture of the materials. With sodium hydroxide solution $(\mathrm{NaOH})$ and sulfuric acid solution $\left(\mathrm{H}_{2} \mathrm{SO}_{4}\right)$, yield stress increased by heat treatment, this being the dominant factor for decrease in toughness.

\section{REFERENCES}

1. M. Ishikawa, I. Narisawa, and H. Ogawa, J. Polym. Sci., Polym. Phys. Ed., 15, 197 (1977).

2. M. Ishikawa, H. Ogawa, and I. Narisawa, J. Macromol. Sci., Phys. B, 19, 421 (1981).

3. M. Ishikawa and I. Narisawa, J. Mater. Sci., 18, 1974 (1983).

4. M. Ishikawa and I. Narisawa, J. Mater. Sci., 18, 2826 (1983).

5. M. Ishikawa, S. Taniguchi, and I. Narisawa, Polym. Prepr.
Jpn., 37, 969 (1988).

6. M. Ishikawa, Polym. Prepr. Jpn., 40, 796 (1991).

7. M. Ishikawa and H. Takahashi, J. Mater. Sci., 26, 1295 (1991).

8. A. S. Argon, Philos. Mag., 28, 839 (1973).

9. A. S. Argon and M. I. Bessonov, Philos. Mag., 35, 917 (1977).

10. B. Crist, C. J. Fisher, and P. R. Howrd, Macromolecules, 22, 1709 (1989).

11. M. Sugimoto, M. Ishikawa, and K. Hatada, Polym. Prepr. Jpn., 42, 4408 (1993).

12. M. Ishikawa, M. Sugimoto, K. Hatada, and N. Tanaka, Kobunshi Ronbunshu, 52, 149 (1995).

13. M. Sugimoto, M. Ishikawa, and K. Hatada, Polymer, 36, 3675 (1995).

14. M. Ishikawa, M. Sugimoto, K. Hatada, and T. Tanaka, Kobunshi Ronbunshu, 52, 134 (1995).

15. M. Ishikawa and I. Chiba, Polymer, 30, 1232 (1990).

16. M. Ishikawa and I. Narisawa, J. Mater. Sci., 13, 2826 (1983).

17. W. R. Krigbaum, R. J. Roe, and K. J. Smith, Jr., Polymer, 5, 533 (1964).

18. R. Segula and R. Fietsch, J. Mater. Sci., 23, 1233 (1988). 